\title{
КИБЕРПРОСТРАНСТВО CYBERSPACE
}

DOI: 10.17803/1729-5920.2020.166.9.108-118

М. В. Мажорина*

\section{Право сетевого общества и проблема управления гибридностью1}

Аннотация. Сетевое общество, актуальное для социального ландшафта XXI в., предопределяет выстраивание новой архитектуры права. Современная правовая карта мира крайне неоднородна и зачастую не совпадает с политической картой мира. Она пестрит самыми разными нормативными массивами, которые коллидируют друг с другом, наслаиваются друг на друга, в то время как традиционная правовая методология не всегда способна разрешить возникающие коллизии. Значительный потенциал обретает проблема коллизии права и неправа ввиду стремительного разрастания неправовой материи и появления легитимизирующих ее институций. Ситуация осложняется одновременным существованием нескольких институциональных систем разрешения споров (государственных, негосударственных, альтернативных, платформенных), которые обращаются к совершенно разным, относительно автономным подсистемам норм как к применимому праву. Такая материальная и институциональная фрагментация, появление гибридных нормативных и институциональных режимов провоцируют активный поиск новых принципов построения правовой архитектуры, адекватной столь быстро меняющемуся обществу. Глобализация трансформируется в сетевизацию, которая переопределяет географию мира, известные и традиционные принципы аффилиации субъектов права, а следом обостряет полемику о правовой таксономии. Обозначенная эволюция правовой надстройки также порождает новые типы коллизий, побуждая к поиску новой или адаптации известной методологии для целей их преодоления.

В работе предпринимается попытка исследовать новую нормативность в условиях новой социальности, определить ключевые тренды развития права сетевого общества, спрогнозировать развитие отдельных правовых и субправовых институтов, смоделировать правовые способы управления гибридностью.

Ключевые слова: сеть; сетевое право; глобальное право; транснациональное право; международное частное право; негосударственное регулирование; коллизия права и неправа; lex mercatoria; платформенное право; международный коммерческий арбитраж.

Для цитирования: Мажорина М. В. Право сетевого общества и проблема управления гибридностью // Lex russica. - 2020. - T. 73. - № 9. - C. 108-118. - DOI: 10.17803/1729-5920.2020.166.9.108-118.

1 Исследование выполнено при финансовой поддержке РФФИ в рамках научного проекта № 18-29-16061.

(C) Мажорина М. В., 2020

* Мажорина Мария Викторовна, кандидат юридических наук, доцент, доцент кафедры международного частного права Московского государственного юридического университета имени О.Е. Кутафина (МГЮА)

Садовая-Кудринская ул., д. 9, г. Москва, Россия, 125993

mvmazhorina@msal.ru 


\title{
The Law of the Network Society and the Problem of Hybridity Management ${ }^{2}$
}

\author{
Mariya V. Mazhorina, Cand. Sci. (Law), Associate Professor, Associate Professor of the Department \\ of International Law, Kutafin Moscow State Law University (MSAL) \\ ul. Sadovaya-Kudrinskaya, d. 9, Moscow, Russia, 125993 \\ mvmazhorina@msal.ru
}

\begin{abstract}
The network society, which is relevant to the social landscape of the 21st century, determines the building of a new architecture of law. The current legal map of the world is extremely heterogeneous and often does not coincide with the political map of the world. It is full of a variety of normative arrays that collide with each other, layered on top of each other, while the traditional legal methodology is not always able to resolve conflicts that arise. The problem of controversy between law and not law is gaining considerable potential due to the rapid growth of non-legal matter and the emergence of legitimizing institutions. The situation is complicated by the simultaneous existence of several institutional dispute resolution systems (state, non-state, alternative, platform-based) that refer to completely different, relatively autonomous subsystems of norms as applicable law. Such material and institutional fragmentation, the emergence of hybrid regulatory and institutional regimes has provoked an active search for new principles of building a legal architecture that is adequate to such a rapidly changing society. Globalization is transforming into networking, which redefines the geography of the world, the well-known and traditional principles of affiliation of legal entities, and then exacerbates the debates about legal taxonomy. The marked evolution of the legal superstructure also generates new types of conflicts, prompting the search for a new or adaptation of the known methodology in order to overcome them.

The paper attempts to explore the new normativity in the context of a new sociality, to identify key trends in the development of the law of a network society, to predict the development of individual legal and sub-legal institutions, and to model legal ways of managing hybridity.

Keywords: network; network law; global law; transnational law; private international law; non-state regulation; controversy between law and not law; lex mercatoria; platform law; international commercial arbitration.

Cite as: Mazhorina MV. Pravo setevogo obshchestva i problema upravleniya gibridnostyu [The Law of the Network Society and the Problem of Hybridity Management]. Lex russica. 2020;73(9):108-118. DOI: 10.17803/17295920.2020.166.9.108-118. (In Russ., abstract in Eng.).
\end{abstract}

\section{Новая нормативность в условиях новой социальности? Некоторые актуальные взгляды на правовую таксономию}

Сетевой подход к изучению окружающего мира, по некоторым воззрениям, берет свое начало в 1735 г. и связывается с именем математика Л. Эйлера, который сформулировал решение задачи о семи кёнигсбергских мостах ${ }^{3}$, заложив основу теории графов. Важной вехой в развитии этой теории стала середина прошлого столетия, когда венгерскими математиками Эрдешем и Реньи была создана теория случайных графов, ставшая основным направлением изучения сетевых структур вплоть до конца XX в. ${ }^{4}$ Сетевая методология широко применяется в математике, физике, биологии, для структурирования информационных, технологичных сетей. При этом социальные сети всегда имели в истории достаточно большое значение, особенно важную роль они сыграли, по мнению Н. Фергюсона, в двух следующих эпохах: первая «сетевая эпоха» наступила вслед за появлением печатного станка в Европе в конце XV в. и продлилась до конца XVIII в. Вторая - наша собственная - началась в 1970-х гг. ${ }^{5}$

Исследователи всерьез говорят о формировании радикально новой структуры мира, стиля мышления, моделей поведения, образа жизни человека, будучи сходны в том, что

2 The reported study was funded by RFBR according to the research project № 18-29-16061.

3 Euler L. Seven Bridges of Königsberg // The World of Mathematics. 2000. Vol. 1. Pp. 573-580.

4 См.: Евин И. А. Теория сложных сетей как новая научная парадигма // URL: http://spkurdyumov.ru/ uploads/2013/09/evvvin.pdf (дата обращения: 05.02.2019).

5 Фергюсон Н. Площадь и башня. Сети и власть от масонов до Facebook. М. : АСТ: Corpus, 2020. С. 20. 
сеть - это фундаментальный феномен бытия ${ }^{6}$. В этой связи значимый вклад в развитие социального концепта «сетевого общества» внес М. Кастельс ${ }^{7}$. Исследователи используют разные термины для обозначения феномена нашего времени: «сетевой век», «эпоха власти глобальных систем», «век вовлечения» ${ }^{8}$, а американский политолог П. Ханна аргументированно пишет о коннектографии как дисциплине, в некотором смысле подменяющей географию9

Право традиционно находится в статусе догоняющего по отношению к своему базису - социуму, скорость изменений в котором значительно возросла с распространением информационно-коммуникационных технологий. Председатель Конституционного Суда РФ В. Д. Зорькин указывает на тенденцию «отставания нормативно-правовой регламентации хозяйственно-правовых отношений от изменений социального содержания этих отношений, заметно ускоряющихся по мере развития процессов глобализации» ${ }^{10}$. Американский судья Л. Д. Брандейс также пишет, что «закон повсеместно имеет тенденцию отставать от жизни» ${ }^{11}$.

Консервативная локализованность права диссонирует с принципами сетевого пространства, перестраивающими социум. Первопричиной «отставания» права от социальной реальности XXI в. является процесс, подмеченный М. Кастельсом, который считает, что мир сегодня выстраивается в логике пространства потоков, а люди пытаются продолжать жить в пространствах мест ${ }^{12}$. Сходную мысль высказывает У. Бек: транснационализация социального пространства ведет к тому, что аннулируется привязка людей и общностей к определенному месту. Мир больше не является совокуп- ностью сообществ, замкнутых в рамках того или иного пространства. Постепенно рушится структура основных принципов, на которых до сих пор организовывались и жили общества и государства, представляя собой территориальные, отграниченные друг от друга единства. Глобализация переопределила территориальные границы применения власти ${ }^{13}$. Закон уже «выплеснулся» за пределы национального государства ${ }^{14}$, границы правовых режимов расходятся с государственными границами, и число правовых режимов уже вовсе не обязательно должно соответствовать числу государств ${ }^{15}$. Переосмысление территории и национальных государственных границ, традиционных принципов аффилиации субъектов права и прочие процессы, меняющие мироустройство в условиях сетевого общества, заставляют государства переориентироваться в части поиска регуляторных моделей, адекватных новым типам взаимодействия субъектов.

Это порождает принципиально важные последствия для права: национальное право, объективированное вовне в источниках, созданных или санкционированных государством, являет собой право локальное по своей природе, действующее, как правило, в рамках границ государств-правотворцев. Его территория, с одной стороны, “сжимается» за счет расширения правового ландшафта, создаваемого теми же государствами, но с применением иного инструментария - международной унификации, нивелирующей различия национальных правопорядков. В результате право становится сходным, но не тождественным, не демонстрируя признаков сращивания в единую глобальную систему. С другой стороны, право «запаздыва-

6 См.: Игнатов М. А. Сетевая парадигма (Философская рефлексия) // URL: https://cyberleninka.ru/ article/n/setevaya-paradigma-filosofskaya-refleksiya (дата обращения: 08.02.2019).

7 Castells $M$. The Information Age. Economy, Society, and Culture. The Rise of the Network Society Second edition with a new preface. Oxford: Wiley-Blackwell, 2010. P. 501.

8 См.: Фергюсон Н. Указ. соч. С. 38.

9 Ханна П. Коннектография. Будущее глобальной цивилизации. М. : Манн, Иванов и Фербер, 2019. 432 с.

10 Зорькин В. Д. Право в условиях глобальных перемен. М. : Норма, 2013. С. 114.

11 Brandeis L. D. The Living Law // URL: http://www.minnesotalegalhistoryproject.org/assets/Brandeis-Living\%20Law.pdf (дата обращения: 08.02.2019).

12 Castells M. The Information Age. Economy, Society, and Culture. The Rise of the Network Society Second edition with a new preface. Oxford : Wiley-Blackwell, 2010.

13 Beck U. Power in the Global Age: a New Political Economy. Cambridge : Polity Press, 2005. P. 50.

14 Cotterrell R. What Is Transnational Law? // Law \& Social Inquiry. 2012. Vol. 37. Iss. 2. Pp. 500-524.

15 Fischer-Lescano A., Teubner G. Regime-Collisions: The Vain Search for Legal Unity in the Fragmentation of Global Law // Michigan Journal of International Law. 2004. Vol. 25. Pp. 999-1046. 
ет», и появляется значительный объем трансграничных общественных отношений, которые лежат вне зоны регулирования международных унифицированных норм. Зона «отставания» замещается другими нормативными регуляторами, созданными частными субъектами, и этот нормативный массив - суть «право» глобальное, транснациональное, не детерминированное границами государств.

Е. А. Войниканис, обращая внимание на эффект запаздывания права, выстраивает последовательность: за изменением ситуации в обществе, экономике и культуре вначале следуют спонтанные изменения на уровне негосударственного права, и только затем, после продолжительных дебатов в академической среде и изменения соответствующей позиции в политических кругах, изменения приходят и в законодательство ${ }^{16}$. Иными словами, социально-правовой «разрыв» на определенном историческом этапе заполняется нормами негосударственного регулирования, что происходит сегодня, будучи признаком переходного социального этапа развития общества. Смена контекста ведет к появлению «гибридных нормативных режимов» ${ }^{17}$ или «гибридных правовых пространств» и проблеме «управления гибридностью» ${ }^{18}$, актуализирует проблему коллизии права и неправа и поиска новой методологии.

В условиях, когда современное общество впадает в колоссальную зависимость от цифровых ресурсов и технологий, пробелы в правовом регулировании множатся, так как право не способно быстро продуцировать надлежащий нормативный материал. Функцию восполнения пробелов берет на себя широко масштабируемое негосударственное регулирование. Над созданием будущего права активно работают не только государственно-властные образования, но и частные акторы: мировое бизнес-сообщество или бизнес-элиты в лице транснациональных организаций, надгосударственные и негосударственные структуры. Во многих сегментах мирового сообщества, таких как глобальная экономика, наука, технология, СМИ, спорт, торговля, наблюдается активное формирование нормативных режимов, которые лежат за пределами национального законодательства или международных договоров, наиболее заметными из которых являются lex mercatoria, lex sportiva, lex digitalis / lex informatica / lex electronica / lex constructionis, lex petrolia, право мировых торговых площадок (ebay-law, Walmart law). А. Маурер достаточно аргументированно пишет о транснациональном морском праве, о серьезном значении частного нормотворчества в этой области ${ }^{19}$.

Как в этих условиях выстраивается правовая таксономия? В российской и иностранной правовых доктринах появляется всё больше концепций, нацеленных на объяснение сосуществования и «примирение» различных систем норм (правовых и неправовых) в одном и том же географическом и социальном пространстве. Эти концепции в той или иной степени размывают границы между правом и неправом, нацелены на нивелирование ригидности позитивистского подхода к праву и служат теоретическим основанием идеи гибридных правовых пространств.

Я. М. Смитс по-новому интерпретирует идеи Ф. К. фон Савиньи, который рассматривал право как явление, внутренне связанное с обществом и развивающееся как единый организм, с той разницей, что современное право по-прежнему связано с обществом, но это общество состоит в первую очередь из культурных сегментов, пересекающих национальные границы государств. И задачей будущего является выявление таких сегментов ${ }^{20}$.

По мнению Г. Тойбнера, в центре современной правовой системы лежит официальный закон, применяемый судами, тогда как на периферии - широкий спектр нормативных

16 Войниканис Е. А. Парадигмальный сдвиг в современном праве // Философия политики и права : сборник научных работ. М. : Изд. Воробьев А. В., 2010. Вып. 1. С. 138-161.

17 De Carolis $D$. The process of harmonisatin of the law of international commercial arbitration: drafting and diffusion of uniform norms : Doctoral Thesis. URL: http://eprints-phd.biblio.unitn.it/214/1/dissertation.pdf (дата обращения: 22.10.2017).

18 Berman P. S. Global Legal Pluralism // Southern California Law Review. 2007. Vol. 80. Pp. 1155-2007.

19 Maurer A. Transnational Maritime Law // The Hamburg Lectures on Maritime Affairs 2011-2013 / J. Basedow, U. Magnus, R. Wolfrum (eds.). Hamburg : Springer, 2014. Pp. 129-146.

20 Smits J. M. Legal Culture as Mental Software, or: How to Overcome National Legal Culture? Private Law and the Many Cultures of Europe. The Hague : Kluwer Law International, 2007. Pp. 150-151. 
порядков гибридного или квазиправового характера, наиболее ярким примером последних является lex mercatoria ${ }^{21}$.

Объективно видимой представляется сегодня иная систематизация права в зависимости от степени локализации правовых массивов, территориальной привязки и детерминированности. В этой связи можно говорить, с одной стороны, о локальном праве, «произрастающем» из определенной территории, коим может быть внутригосударственное право, право субъекта (штата, кантона и пр.), право общины и пр. Речь идет об этаком «корневом» праве, выстроенном на постулатах позитивизма и прочно связанном с государством как производящим его субъектом. Ему условно противостоит транснациональное право, делокализация и децентрализация которого суть его ключевые критерии, не означающие, однако, что оно лишено «корней».

Распространение цифровых технологий обеспечило выстраивание новой модели коммуникации социума. Компьютерные технологии создали особенную форму распределенной коммуникации, которую оказалось возможным спроецировать на социальную коммуникацию ${ }^{22}$. Цифровые сетевые технологии позволяют индивидам и организациям генерировать собственный контент, распространяя его в киберпространстве и в значительной степени избегая контроля корпораций и бюрократических структур. Происходит сдвиг в сторону массовой самокоммуникации, ставшей возможной благодаря Интернету. При этом такая свободная коммуникация, как пишет М. Кастельс, бросает вызов властным отношениям, укорененным в общественных институтах и организация ${ }^{23}$. Идеи децентрализации, конструирования автономии и неподвластности привлекают сегодня, например, разработчиков и пользователей технологии блокчейн, которая является одним из новых способов регулирования сетевых отношений. Новая архитектура современных сетей выстраивается не в духе вертикально организованных, централизованных, устойчивых иерархичных структур, а в логике горизонтальной, децентрализованной, масштабируемой самокоммуникации, способность цифровой идентификации субъектов которой и управления последними переопределяет актуальное мироустройство.

Сеть и информационные технологии коммуникации становятся паттернами современного мироустройства, а потому оказывают заметное воздействие на право. Соответствующие социальные сдвиги приводят к масштабированию регуляторов, отличных от правовых норм, детерминированных государством. Во многих сферах правового регулирования: от прав человека и защиты окружающей среды до международных финансовых операций - широкое распространение получили международные стандарты, которые, не будучи юридически обязательными, тем не менее в разных формах оказывают беспрецедентное воздействие на регулирование соответствующих отношений. Они в совокупности с механизмами их распространения и внедрения в нормативное поле даже получили название «транснациональных регулирующих сетей» 24 .

Т. Я. Хабриева, в том числе применительно к оценке цифровой реальности права, совершенно справедливо свидетельствует о переходе системы права к новой структурной организации, особое место в которой занимают нетипичные нормативные массивы, которые не могут быть идентифицированы в прежней категориальной матрице и отнесены к числу известных элементов системы права. Такие, в терминологии автора - «циклические» правовые массивы проникают в большинство элементов системы права, взаимодействуют с ними, определяют их содержание, функционирование, а также векторы и темпы преобразований. Происходит перенастройка права ${ }^{25}$. Фактически о

21 Teubner G. Breaking Frames: Globalization and the Emergence of Lex mercatoria // European Journal of Social Theory. 2002. Vol. 5. No. 2. Pp. 205-211. См. также: De Carolis D. Op. cit.

22 Назарчук А. В. Сетевое общество и его философское осмысление // Вопросы философии. 2008. № 7. С. 62.

23 Кастельс М. Власть коммуникации : учебное пособие : пер. с англ. М. : Изд. дом Высшей школы экономики, 2017. С. 10-11.

24 Verdier P.-H. Transnational Regulatory Networks and Their Limits // The Yale Journal of International Law. 2009. Vol. 34. Pp. 113-172 ; Gadinis S. Three Pathways to Global Standards: Private, Regulator, and Ministry Networks // American Journal of International Law. 2015. Vol. 109. Iss. 1. P. 109.

25 Хабриева Т. Я. Циклические нормативные массивы в праве // Журнал российского права. 2019. № 12. С. 5. См. также: Хабриева Т. Я., Черногор Н. Н. Право в условиях цифровой реальности // Журнал российского права. 2018. № 1. С. 85-102. 
такой перенастройке рассуждают сегодня многие ученые, исследуя ее под разными углами.

Современная юридическая наука все чаще оперирует такими понятиями, как «глобальное право», "транснациональное право», "мировое право» и пр. Эти новые нормативные массивы обслуживают новую архитектуру мира. Использование термина «транснациональное право» как продукта сетевого общества видится предпочтительным, так как он подчеркивает мультисоциальность, акцептирует особую распределенность социумов в пространстве и демонстрирует то, что регулирование пересекает границы государств, обладает экстерриториальным характером. Транснациональность не означает однородности, но свидетельствует о природе происхождения норм, а также о предмете регулирования - отношениях, выходящих за пределы территории одного государства.

\section{Право сетевого общества, гибридность нормативного регулирования, новые типы коллизий и методология их разрешения}

Сетевое общество характеризует некое «несплошное» покрытие относительно больших географических и социальных пространств ${ }^{26}$. Сетевые эффекты в условиях новых технологических возможностей не могут не влиять на право, как бы оно, в силу своей консервативности, не сопротивлялось тому. В этой связи транснациональное право, будучи надстройкой сетевого общества, само по природе может быть определено как сетевое право (lex networkia).

Интерес среди правовых изысканий представляет исследование П. Ш. Бермана, который, будучи последовательным противником концепции единого глобального права, оспаривает строгую привязку субъектов к территориальному расположению в пределах географических границ и развивает космополитичную концепцию выбора права. При определении применимого права к спору судам, по мнению автора, следует учитывать разнообразие нормативных систем, имеющих связи с соответствующим спором. При этом судьи, идентифицируя себя как часть взаимосвязанной сети национальных, транснациональных и международных норм, смогут развивать юриспруденцию, отражающую эту космополитическую реальность ${ }^{27}$. Фактически речь идет о гибридности нормативного регулирования и об управлении гибридностью, когда правоприменительный орган должен не просто акцептировать нормы негосударственного происхождения, но и выстроить иерархию их применения по отношению к спору, являющемуся предметом разбирательства.

Примером управления гибридностью служит п. 32 постановления Пленума ВС РФ от 09.07.2019 № 24, где указано, стороны договора, осложненного иностранным элементом, могут выбрать право страны, которая не имеет связей с договором или его сторонами (выбор нейтрального права). Стороны также вправе выбрать документы, содержащие правила, рекомендованные участникам оборота международными организациями или объединениями государств (например, Принципы международных коммерческих договоров УНИДРУА, Европейские принципы договорного права, Модельные правила европейского частного права). Такие правила применяются только при наличии прямо выраженного соглашения сторон. Вопросы, которые не могут быть решены в соответствии с такими выбранными сторонами документами, а также общими принципами, на которых они основаны, подлежат разрешению в соответствии с внутригосударственным правом, определенным в соответствии с соглашением сторон или коллизионными нормами ${ }^{28}$. Это означает, что ВС РФ допускает выбор сторонами в качестве права, применимого к трансграничным договорным обязательствам, как права, так и «неправа». В последнем случае право будет играть роль субсидиарного статута, к которому можно будет прибегнуть в случае пробела в «неправе». Эта совершенно беспрецедентная трактовка автономии воли сторон в условиях серьезных социальных сдвигов фактически означает, что очень неоднородное, фрагментированное, стратифицированное правовое пространство, само по себе находящееся в поиске ориентиров для упорядочения, колли-

26 Valdman I. A. The network structures: virtualization and adaptation in modern society // Philosophy of Education. Special issue. 2009. Vol. 2. Pp. 141-146.

27 Berman P. S. Towards a Cosmopolitan Vision of Conflict of Laws: Redefining Governmental Interests in a Global Era // University of Pennsylvania Law Review. 2005. Vol. 153. P. 1861.

28 Постановление Пленума Верховного Суда РФ от 09.07.2019 № 24 «О применении норм международного частного права судами Российской Федерации» // СПС «Гарант». 
дирует со стремительно масштабируемым негосударственным массивом норм, исходящим от негосударственных акторов. Такое состояние нормативной надстройки может быть охарактеризовано как коллизия права и неправа ${ }^{29}$.

Это отчасти перекликается с космополитичным подходом П. Ш. Бермана, согласно которому судья не ограничен в выборе одного национального правопорядка, но может разрабатывать/применять гибридные правила, нормы международных договоров и транснациональные нормы, а также учитывать принадлежность субъекта к сообществу, которая не связана с национальными государствами, и, соответственно, применять отраслевые стандарты, правила поведения, разработанные неправительственными организациями, обычаи и пр. ${ }^{30}$ Аффилированность субъекта с тем или иным сообществом (в том числе негосударственным) есть ключевой критерий, подлежащий оценке при выборе применимого к спору права, в логике П. Ш. Бермана. Можно выстроить следующий коллизионный нарратив: от закона страны суда (lex fori) через закон наиболее тесной связи (proper law) к нормам сообщества (rules of community), с которым субъект права себя идентифицирует или имеет наиболее тесную связь.

Нельзя в этой связи не упомянуть о работах Р. Коттеррелла, который считает именно «сообщество» центральным понятием современной правовой теории и развивает концепт права через призму национальных, субнациональных или транснациональных сообществ для целей переориентации современных доктринальных правовых исследований ${ }^{31}$. Он подмечает и такое явление: судьи разных стран опираются на решения и доводы друг друга, это приводит к формированию транснациональных судебных сообществ $^{32}$, что особенно ярко проявляет себя в области международного коммерческого арбитража.
Космополитичный взгляд на коллизионную методологию коррелирует с воззрениями немецких ученых Г. Тойбнера и А. Фишера-Лескано относительно межсистемного коллизионного права, происходящего не из коллизии отдельных национальных правопорядков, но в связи с коллизией различных глобальных социальных секторов ${ }^{33}$. И выбор применимого права в контексте такого подхода должен быть основан не на определении национального права, наиболее тесно связанного со спорным отношением, но на отыскании того функционального режима, к которому относится рассматриваемый правовой вопрос ${ }^{34}$.

Г. Тойбнер также пишет о возникновении новых коллизий, которые не исчерпываются столкновением двух и более национальных правопорядков и обусловлены во многом фрагментацией мирового социума и сообразного ему права. Автор отмечает двойной характер фрагментации: во-первых, функциональная дифференциация современного общества вызывает коллизии между различными автономными глобальными функциональными системами норм; во-вторых, различия между социальными организационными принципами вызывают столкновения между формальным правом современного общества и социально укорененными правовыми системами коренных народов. Так, автор приводит в качестве примеров коллизии национальных правовых порядков с нормами транснационального права - lex digitalis; норм международного права и права коренных культур ${ }^{35}$.

Действительно, сегодня несложно представить себе коллизию между нормами ICANN и каким-либо национальным правопорядком в части регулирования отношений, связанных с сетью Интернет и доменными именами. «Новизна» такой коллизии заключается в том, что одна из коллидирующих сущностей является

29 См. об этом: Мажорина М. В. О коллизии права и «неправа», реновации lex mercatoria, смарт-контрактах и блокчейн-арбитраже // Lex russica. 2019. № 7 (152). С. 93-107.

30 Berman P. S. Towards a Cosmopolitan Vision of Conflict of Laws. P. 1862.

31 Cotterrell R. Community as a Legal Concept? Some Uses of a Law-and-Community Approach in Legal Theory // Queen Mary University of London, School of Law Legal Studies Research Paper No. 95/2011.

32 Cotterrell R. What Is Transnational Law? P. 500.

33 Fischer-Lescano A., Teubner G. Op. cit. Pp. 999-1000.

34 Teubner G. Two Kinds of Legal Pluralism: Collision of Transnational Regimes in the Double Fragmentation of World Society // URL: https://www.researchgate.net/publication/228241875_Two_Kinds_of_Legal_ Pluralism_Collision_of_Transnational_Regimes_in_the_Double_Fragmentation_of_World_Society (дата обращения: 03.05.2020).

35 Teubner G. Two Kinds of Legal Pluralism. 
не национальным правопорядком, а системой норм негосударственного регулирования, «фрагментом» lex mercatoria - lex digitalis, своего рода автономной функциональной системой норм. Политики, принятые Советом директоров частной корпорации ICANN, зарегистрированной в соответствии с законом штата Калифорния, которые должны соблюдаться регистраторами доменных имен - частными корпорациями, ответственными за всемирное распределение доменных имен, - не находятся, на первый взгляд, в поле зрения радара коллизионного права, созданного для разрешения столкновения национальных правопорядков. Но беспрецедентное разрастание неправовой материи вкупе с масштабированием общественных отношений, опосредуемых цифровой средой, укореняет коллизию права и неправа и требует выработки соответствующей методологии.

Важной в этой связи является постановка вопроса о том, что́ вызывает к жизни необходимость акцептирования соответствующей коллизии и поиска методологии ее решения? Если предположить, что речь идет о коллидировании правовых норм с социальными нормами, то в контексте позитивистского подхода к праву ответ становится очевидным и коллизия как таковая фактически отсутствует. Однако объективная реальность такова, что политики ICANN, используемые в качестве примера выше, не могут быть просто проигнорированы, более того, оценка применимости соответствующих норм осуществляется судом именно через призму коллидирования последних с национальным правом. Собственно, принципиальна, как представляется, функциональная природа регулируемых отношений.

Р. Михаэльс определяет происходящие изменения как осмысление модификации права от сегментарной дифференциации на основе государственной локализации в сторону функциональной дифференциации по различным режимам, считая последнее находкой теории права и социологии права ${ }^{36}$.

Это ведет к концептуализации новых типов коллизий: коллизии права и неправа через призму нормативно-правовой эклектики и выбора между неоднородными регулятивными массивами. Сетевизация общества и глобализация экономик не приводит к формированию глобального государства и глобального права, но вместо унификации и однородности в области нормативного регулирования мы фактически получаем коллидирование ряда структурно замкнутых нормативных систем, детерминированных своими источниками нормотворчества и механизмами нормоприменения, каждая из которых претендует на преимущественное применение в соответствующих институциях. Важно то, что нормативная фрагментация сопряжена с институционной, что ведет к еще большему расслоению регуляторных систем. Параллельно развиваются два тренда: с одной стороны, право (скорее, его пробелы) замещается нормами негосударственного регулирования, с другой стороны, споры уходят из судов в плоскость альтернативного регулирования. Яркими примерами тому становятся транснациональные компании платформенного типа, которые продуцируют собственное «право», применимое в рамках собственных систем разрешения споров, как то eBay, Google, Amazon и пр. В науке это приводит к формированию концепта права мировых торговых площадок, или «платформенного права» (the Law of Platform / Platform Law) ${ }^{37}$, подвидами которого становятся еВауlaw $^{38}$, Walmart law ${ }^{39}$ и пр. ${ }^{40}$ В сегменте платформ трансформируются не только принципы регулирования отношений, но и существенным образом перенастраиваются принципы разрешения споров, например происходит серьез-

36 Michaels $R$. The Re-State-Ment of Non-State Law: The State, Choice of Law, and the Challenge from Global Legal Pluralism. Wayne Law Review. 2005. Vol. 51. P. 1213.

37 Lobel O. The Law of the Platform // Minnesota Law Review. 2016. Vol. 101 ; Katyal S. K., Grinvald L. C. Platform Law and the Brand Enterprise // Berkeley Technology Law Journal. 2017. Vol. 32. Pp. 1135-1182.

38 González A. G. eBay Law: The legal implications of the C2C electronic commerce model. Computer Law \& Security Review. Vol. 19, Iss. 6, December 2003. Pp. 468-473 ; Katsh E., Rifkin J., Gaitenby A. E-Commerce, E-Disputes, and E-Dispute Resolution: In the Shadow of «eBay Law». Ohio State Journal on Dispute Resolution, Vol. 15, no. 3 (2000). Pp. 705-734.

39 Backer L. C. Economic Globalization and the Rise of Efficient Systems of Global Private Lawmaking: Wal-Mart as Global Legislator. Connecticut Law Review. Vol. 39. May 2007. Number 4. Pp. 3-46.

40 См. об этом: Мажорина М. В. Цифровые платформы и международное частное право, или есть ли будущее у киберправа? // Lex russica. 2019. № 2 (147). С. 107-120; Мажорина М. В. Мировая экономика 
ный сдвиг от механизма ответственности в сторону репутационных рисков.

Г. Тойбнер приходит к выводу, что фрагментация общества требует от нас расширить понятие права, чтобы оно охватывало нормы, лежащие за пределами правовых источников национального государства и международного права ${ }^{41}$. Это, безусловно, является реакцией на формирование и активное развитие неких достаточно автономных «транснациональных сущностей», которые включают в себя институциональные каркасы и нормативные массивы, моделирующие новые регуляторные модели общественных отношений, не детерминированные государствами, но коллидирующие с источниками национального и международного права.

Коллизионное право выступает сегодня той отраслью права, для которой заявленная полемика представляет практическую важность, в том числе в контексте разрешения споров в международном коммерческом арбитраже, с использованием иных негосударственных институций, платформ, в том числе множащихся под воздействием развития цифровых технологий. Сложно спорить с Р. Михаэльсом, считающим, что площадка коллизионного права становится наилучшим форумом для обсуждения практических последствий правового плюрализма ${ }^{42}$. Подобные мысли посещают и П. Ш. Бермана, который сравнивает коллизию права с полигоном, где со временем должны быть отработаны все важнейшие проблемы глобализации ${ }^{43}$. Как образно замечают А. Райлз и Ф. Джонс, международное частное право дает нам метафору мира, в котором государства всё еще в значительной степени сохраняют присутствие, но часто распадаются или преломляются посредством частных интересов ${ }^{44}$. В иностранной литературе также встречается оценка международного частного права как децентрализованной сети самостоятельно выбранных и индивидуально настроенных правил ${ }^{45}$. Все это подчеркивает методологические особенности международного частного права, обладающего значительным потенциалом в части подстройки под формирующиеся особенности сетевого общества, которые могут быть при необходимости экстраполированы на иные общественные отношения.

Небезынтересными в этой связи являются рассуждения Г. Динвуди, который пытается адаптировать методологию международного частного права к трансграничным спорам в области авторского права, одновременно обращаясь к методологии гибридного нормотворчества. Так, автор исходит из того, что, разрешая трансграничные авторские споры, суды не должны ограничиваться механистическим выбором того или иного национального права, применимого к спору, но должны фактически выработать/применить нормы из смеси национальных и международных норм. Автор движется в своих выводах от локализации к интернационализации авторского права ${ }^{46}$.

Эти и иные подходы, сводимые, по сути, к очень серьезной полемике правопонимания и правовой таксономии, есть попытки преодолеть «генетические черты» государствоцентричной модели права, в которой право детерминировано государством и производно от него. Последствием этого является плоскостное и статичное ви́дение системы права, в то время как сегодня сам мир и соответствующая ему регулятивная среда обретают черты объемности, многомерности, многоуровневости и динамичности. По мнению Т. Я. Хабриевой, «открытие» в праве «циклических массивов» позволяет по-новому взглянуть на систему и структуру права, которая абстрактно соотносится автором с кристаллической решеткой, характеризующей состояние

цифровых платформ: поиск новых регуляторных моделей // Правовое регулирование цифровой экономики в современных условиях развития высокотехнологичного бизнеса в национальном и глобальном контексте : монография / под общ. редакцией В. Н. Синюкова, М. А. Егоровой. М., 2019. С. 19-33.

41 Teubner $G$. Two Kinds of Legal Pluralism.

42 Michaels R. Op. cit. P. 1227.

43 Berman P. S. Towards a Cosmopolitan Vision of Conflict of Laws. P. 1861.

44 Johns F. E., Riles A. Beyond Bunker and Vaccine: The DNC Hack as a Conflict of Laws Issue // URL: https://www. researchgate.net/publication/313782817_Beyond_Bunker_and_Vaccine_The_DNC_Hack_as_a_Conflict_of_ Laws_Issue (дата обращения: 18.12.2018).

45 Slaughter A.-M. International Law in a World of Liberal States // European Journal of International Law. 1995. Vol. 6. P. 518.

46 Dinwoodie G. B. A New Copyright Order: WMy National Courts Should Create Global Norms // University of Pennsylvania Law Review. 2000. Vol. 149. Pp. 469-580. 
вещества ${ }^{47}$. Такое ви́дение не противоречит новому свойству правовой материи, которое может быть охарактеризовано через призму сети нормативных массивов, которые в динамике выполняют регуляторные, стабилизирующие, стандартизирующие, структурирующие функции. Отдельные нормы, группы норм в сетевом праве имеют характер реагентов, запуская регулирование сверхновых общественных отношений или даже моделируя будущее регулирование, модифицируя имеющееся. Природа таких массивов "реактивных норм», например норм платформенного права, гибридна и мультисодержательна, они зачастую представляют собой сплав правовых, неправовых норм и цифровых технологий, а потому не вписываются в классическую правовую таксономию, которая подвергается существенному риску демонтажа. Одной из ощутимых тенденций становится все более «бесшовный» переход, перетекание норм из одного нормативного массива в другой, формирование подвижных ad hoc нормативных массивов, обслуживающих вновь образуемые массивы общественных отношений. Объемность, многомерность, а потому и гибридность, трансграничность и все нарастающая динамичность сетевого права как надстройки сетевого общества становятся неотъемлемыми свойствами современной системы нормативного регулирования.

\section{БИБЛИОГРАФИЯ}

1. Войниканис Е. А. Парадигмальный сдвиг в современном праве // Философия политики и права : сборник научных работ. - М. : Изд. А. В. Воробьев, 2010. - Вып. 1. - С. 138-161.

2. Зорькин В. Д. Право в условиях глобальных перемен. - М. : Норма, 2013. - 496 с.

3. Хабриева Т. Я. Циклические нормативные массивы в праве // Журнал российского права. - 2019. № 12. - С. 5-18.

4. Хабриева Т. Я., Черногор Н. Н. Право в условиях цифровой реальности // Журнал российского права. 2018. - № 1. - C. 85-102.

5. Berman P. S. Global Legal Pluralism // Southern California Law Abstract. - 2007. - Vol. 80. - Pp. 1155-2007.

6. Berman P. S. Towards a Cosmopolitan Vision of Conflict of Laws: Redefining Governmental Interests in a Global Era // University of Pennsylvania Law Abstract. - 2005. - Vol. 153. - Pp. 1819-1882.

7. Castells M. The Information Age. Economy, Society, and Culture. The Rise of the Network Society. - Second edition with a new preface. - Oxford : Wiley-Blackwell, 2010.

8. Cotterrell R. What Is Transnational Law? // Law \& Social Inquiry. - 2012. - Vol. 37. - Iss. 2. - Pp. 500-524.

9. De Carolis $D$. The process of harmonisatin of the law of international commercial arbitration: drafting and diffusion of uniform norms. Doctoral Thesis // URL: http://eprints-phd.biblio.unitn.it/214/1/dissertation.pdf.

10. Fischer-Lescano A., Teubner G. Regime-Collisions: The Vain Search for Legal Unity in the Fragmentation of Global Law // Michigan Journal of International Law. - 2004. - Vol. 25. - Pp. 999-1046.

11. Katyal S. K., Grinvald L. C. Platform Law and the Brand Enterprise // Berkeley Technology Law Journal. 2017. - Vol. 32. - Pp. 1135-1182.

12. Lobel O. The Law of the Platform // Minnesota Law Abstract. - 2016. - Vol. 101. - Pp. 87-166.

13. Michaels R. The Re-State-Ment of Non-State Law: The State, Choice of Law, and the Challenge from Global Legal Pluralism // Wayne Law Abstract. - 2005. - Vol. 51. - Pp. 1209-1259.

14. Teubner G. Breaking Frames: Globalization and the Emergence of Lex mercatoria // European Journal of Social Theory. - 2002. - Vol. 5. - No. 2. - Pp. 205-211.

15. Teubner G. Two Kinds of Legal Pluralism: Collision of Transnational Regimes in the Double Fragmentation of World Society // URL: https://www.researchgate.net/publication/228241875_Two_Kinds_of_Legal_Pluralism_ Collision_of_Transnational_Regimes_in_the_Double_Fragmentation_of_World_Society.

Материал поступил в редакцию 30 июля 2020 г.

47 См.: Хабриева Т. Я., Черногор Н. Н. Право в условиях цифровой реальности // Журнал российского права. 2018. № 1. С. 85-102. 


\section{REFERENCES}

1. Voynikanis EA. Paradigmalnyy sdvig v sovremennom prave [Paradigm shift in modern law]. In: Filosofiya politiki i prava: sbornik nauchnykh rabot [Philosophy of politics and law: collection of papers]. Moscow: A. V. Vorobyov Publishing House; 2010;1:138-161. (In Russ.)

2. Zorkin VD. Pravo v usloviyakh globalnykh peremen [Law in the conditions of global changes]. Moscow: Norma; 2013. (In Russ.)

3. Khabrieva TYa. Tsiklicheskie normativnye massivy v prave [Cyclical normative arrays in law]. Zhurnal Rossiyskogo Prava [Journal of Russian Law]. 2019;12:5-18. (In Russ.)

4. Khabrieva TYa, Chernogor NN. Pravo v usloviyakh tsifrovoy realnosti [Law in the conditions of digital reality]. Zhurnal Rossiyskogo Prava [Journal of Russian Law]. 2018;1:85-102. (In Russ.)

5. Berman PS. Global Legal Pluralism. Southern California Law Abstract. 2007;80:1155-2007. (In Eng.)

6. Berman PS. Towards a Cosmopolitan Vision of Conflict of Laws: Redefining Governmental Interests in a Global Era. University of Pennsylvania Law Abstract. 2005;153:1819-1882. (In Eng.)

7. Castells M. The Information Age. Economy, Society, and Culture. The Rise of the Network Society. Second edition with a new preface. Oxford: Wiley-Blackwell; 2010. (In Eng.)

8. Cotterrell R. What Is Transnational Law? Law \& Social Inquiry. 2012;37(2):500-524. (In Eng.)

9. De Carolis $D$. The process of harmonisation of the law of international commercial arbitration: drafting and diffusion of uniform norms. Doctoral Thesis. Available from: http://eprints-phd.biblio.unitn.it/214/1/ dissertation.pdf. (In Eng.)

10. Fischer-Lescano A, Teubner G. Regime-Collisions: The Vain Search for Legal Unity in the Fragmentation of Global Law. Michigan Journal of International Law. 2004;25:999-1046. (In Eng.)

11. Katyal SK, Grinvald LC. Platform Law and the Brand Enterprise. Berkeley Technology Law Journal. 2017;32:11351182. (In Eng.)

12. Lobel O. The Law of the Platform. Minnesota Law Abstract. 2016;101:87-166. (In Eng.)

13. Michaels R. The Re-State-Ment of Non-State Law: The State, Choice of Law, and the Challenge from Global Legal Pluralism. Wayne Law Abstract. 2005;51:1209-1259. (In Eng.)

14. Teubner G. Breaking Frames: Globalization and the Emergence of Lex mercatoria. European Journal of Social Theory. 2002;5(2):205-211. (In Eng.)

15. Teubner G. Two Kinds of Legal Pluralism: Collision of Transnational Regimes in the Double Fragmentation of World Society. Available from: https://www.researchgate.net/publication/228241875_Two_Kinds_of_Legal_ Pluralism_Collision_of_Transnational_Regimes_in_the_Double_Fragmentation_of_World_Society. (In Eng.) 